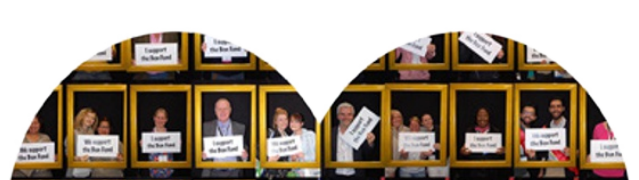

WHY THE BDA

BENEVOLENT FUND MATTERS

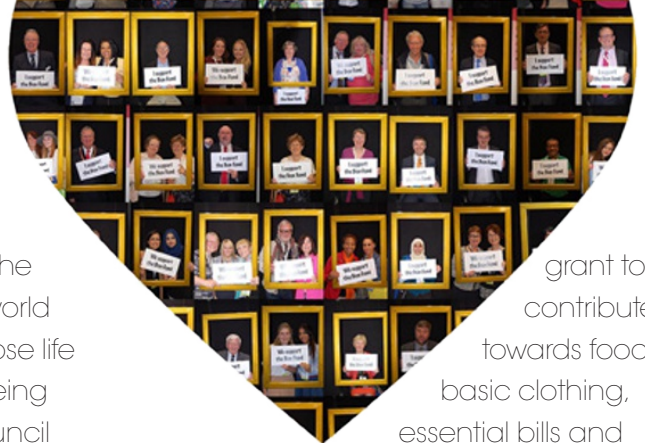

cquitted by the General Dental Council

Health Committee, without the dedicated

work of the BDA Benevolent Fund his

stuation could have been a lot worse.

Run by dentists for dentists, the Fund is

edicated to providing support in times

f financial hardship to those that need it

Ost.

After the Fund gave Dr M a loan to help

with some of his debts and a monthly

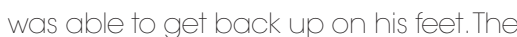

BDA Benevolent Fund relies on your help

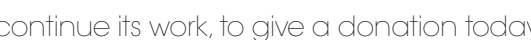

visit wuw.bdabenevolentfund.org.uk

If you are struggling, or know someone

who is, contact the BDA Benevolent

Fund today, call 02074864994 or email

administrator@dentistshelp.org.

\title{
NO HEADACHES AUTOMATIC ENROLMENT
}

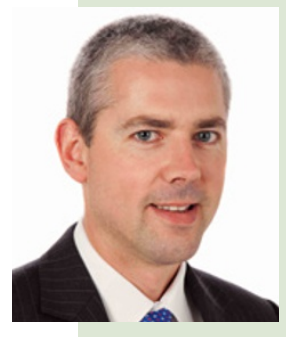

Under new legislation, every employer in the UK must put certain staff into a pension scheme and contribute towards it. This is called 'automatic enrolment' - AE.

Your obligations as an employer are to choose an eligible pension scheme, add your eligible employees to it and coordinate the scheme with your payroll. You must communicate certain information to your staff but do not need to offer them financial advice. You then complete a Declaration of Compliance with The Pensions Regulator (TPR) and all in time for your so-called 'staging date' - obtained from TPR.
To take the headaches out of AE, Chartered Financial Planners PFM Dental, which offers advice exclusively to dentists, provides an $\mathrm{AE}$ set-up service tailored to your requirements. Independent financial adviser, Jon Drysdale, says: "For a fixed fee, we help you with all or just parts of the process. We can help you choose a pension scheme, enrol your eligible employees and coordinate your payroll making sure you're fully compliant by your staging date. And we can advise on complex aspects such as opt-outs, waiting periods and triggers."

For more information go to the Workplace Pensions page on www.pfmdental.co.uk or contact Jon Drysdale on 01904670820.

\section{ALL YOU NEED FOR ALL YOU DO!}

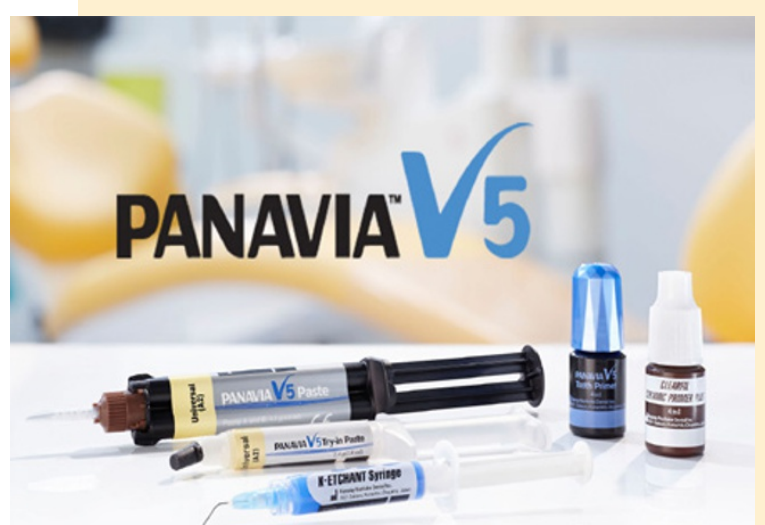

The all new Panavia V5 is a simple, reliable system which works for the cementation of ALL materials including adhesion bridges and veneers in just 3 easy steps

Firstly, patients are treated with the one-step Tooth Primer. The new Clearfil Ceramic Primer Plus is a dental universal prosthetic primer that provides an enhanced adhesive surface to ceramics, hybrid ceramics, composite resins and metals.

This fluoride releasing cementation system comes in automix delivery with a low film thickness and easy removal of excess cement.

For further information on Panavia V5 or any other J\&S Davis products visit www. js-davis.co.uk or call 01438747344
SUB- CONTRACTING - WHAT IS IT ALL ABOUT?

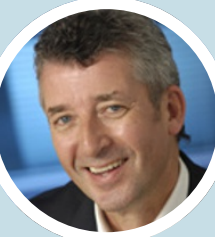

Alan Suggett on sub-contracting

There has been much discussion recently about the difficulties of incorporating an NHS

contract caused by the NHS England Incorporation Policy.

In some situations NHS practice owners are turning to use of a 'sub contract.'

This is usually an arrangement where a limited company is engaged by the NHS contract holder to perform 'clinical matters'.

This arrangement is allowed by GDS contracts, and permission isn't required from NHS England, only notification is necessary.

In simple terms, if structured properly, this can achieve many, but not all, of the objectives of a full blown incorporation.

In particular it can enable profits to be distributed to non-dentists/GDC registrants who are shareholders in the subcontract limited company - unlike dental partnerships which must comprise of registered dental professionals.

It also can enable profits to be retained, after suffering a lower corporate rate of tax, for future practice acquisitions.

What is meant by structured properly? There are many potential pitfalls, and an increased amount of red tape and administration.

A legal agreement is required for the subcontract, and operationally many changes will be required with regard to, for example, staff employment contracts, associate agreements, and practice transactions generally.

Great care and good advice is essential as, believe it or not, if the operational procedures are set up incorrectly, dentists can be excluded from the NHS Pension Scheme, and VAT can become chargeable on some payments.

To find out more about NASDAL, go to www.nasdal.org.uk. 